\title{
A questão da identidade sob o viés da Antropologia do político
}

\author{
Marcus Vinícius Rios Barreto ${ }^{1}$
}

\section{Resumo}

O presente resumo consiste em uma breve discussão acerca da questão da identidade pensada como categoria antropológica sob o viés da Antropologia do político: paradigma teórico-metodológico proposto por Paula Montero, José Maurício Arruti e Cristina Pompa em um ensaio escrito para o livro $O$ Horizonte da Política, organizado por Adrian Gurza Lavalle e publicado em 2012.

Em linhas gerais, esse paradigma pensado pelos três autores é uma ferramenta que permite analisar determinados fenômenos contemporâneos para os quais parece não mais existir a possibilidade de distinção entre aquilo que era identificado como cultura pela Antropologia clássica e o campo das práticas políticas (MONTERO, ARRUTI \& POMPA, 2012, p. 2).

Antes de prosseguirmos nas concepções que definem a Antropologia do político é necessário compreender a crise do conceito de cultura que desde a década de 1980 tem influenciado o campo da Antropologia. Lorenzo Macagno diz que o multiculturalismo, os estudos culturais e os estudos póscoloniais desencadearam nos últimos trinta anos um debate quanto ao monopólio disciplinar da Antropologia, colocando em questão por um lado se a noção de cultura como "substantivo plural" ainda é útil e apontando os

\footnotetext{
1 Mabarreto2003@yahoo.com.br - Projeto de Pesquisa - PPGCS / EFLCH / Unifesp. Orientadora: Profa. Doutora Crisina Pompa
} 
usos políticos que diferentes agentes fazem dessa noção por outro (MACAGNO, 2014, p. 163).

O autor nos alerta para a armadilha da interface "cultura-política(o)" na qual está implícita uma confusão entre o sentido de cultura tradicionalmente utilizado pelos antropólogos e a noção de cultura instrumentalizada por militantes e ativistas nos chamados movimentos sociais fruto das "políticas de reconhecimento" ou "multiculturalismo". Se há uma disputa em prol da legitimidade de um "mundo social" é preciso identificar os agentes envolvidos nessa contenda (Ibid., p. 164). Para ele,

Essa suposta ameaça nasce do fato de que a "cultura" - como matéria de reflexão não é mais um monopólio dos antropólogos. Durante muito tempo, o lugar-comum da crítica antropológica baseou-se no questionamento do chamado culturalismo, o qual muitas vezes funcionou como uma autêntica categoria acusatória. Agora, os próprios antropólogos assistem perplexos à irônica circunstância dos "seus" nativos se terem tornado mais culturalistas do que nunca (Ibid., p. 165).

Adam Kuper faz uma extensa revisão bibliográfica sobre o conceito de cultura nas mais variadas pesquisas realizadas por diferentes antropólogos e afirma que "cultura está na boca de todo mundo". Já no prefácio do seu livro, o autor chama a atenção para o par cultura-política ao dizer que os movimentos sociais cujas bandeiras tem como lemas nacionalismo, identidade étnica ou religião tendem a invocar a cultura no intuito de motivar ações políticas (KUPER, 2002, p. 24).

Nos escritos de Kuper percebemos uma crítica feroz ao uso demasiado desse conceito até porque, segundo o autor, se no âmbito das ciências sociais alguns conceitos desapareceram, certamente isso não se aplica ao conceito 
de cultura. Ele também observa que as pessoas não buscam a orientação dos antropólogos na agenda cultural contemporânea. Elas recorrem aos estudos culturais porque "o debate sobre cultura voltou a ter um caráter político" (Ibid., 289).

Esse panorama de crise epistemológica está no bojo dos argumentos para a formulação da Antropologia do político. Montero, Arruti e Pompa no início do ensaio sugerem que a demarcação chamada por eles de “"o político” deveria ocupar na antropologia contemporânea o lugar teórico-metodológico deixado vago pelo conceito de cultura na antropologia clássica." (MONTERO, ARRUTI \& POMPA, 2012, p. 1).

Para os autores, não mais se sustenta na Antropologia a visão segundo a qual a política seria um contraponto ao conceito de cultura. Isso se deve ao fim da era colonial: período a partir do qual as distinções entre o campo das práticas políticas e aquilo que foi postulado como cultura tornaram-se cada vez menos claras. Na medida em que o conceito de cultura passou a ocupar um lugar e exercer funções no vocabulário político, essa categoria perdeu a eficiência de conceito analítico (Ibid., pp. 1-2).

No que se refere à pós-modernidade, Montero, Arruti e Pompa apontam a crítica pós-moderna e pós-colonial como desestabilizadora do conceito de cultura enquanto ideia antropológica. Tal fato se deve à crise do conceito, já citada nos parágrafos anteriores, fruto do deslocamento dessa categoria de um plano teórico para um plano político onde a mesma é instrumentalizada. Nas palavras deles,

o verdadeiro paradoxo está no fato de que, enquanto a crítica desconstrucionista diluiu o conceito de cultura na noção de texto, de dialogia ou, decididamente de fiction, e enquanto a própria antropologia o repensou em termos de fragmentação, negociação, hibridismo, inconsistências, fluxos de 
relações, a ideia essencialista de cultura torna-se, no plano político, tanto um instrumento de auto-afirmação identitária, quanto uma linguagem jurídica de atribuição de direitos. Desse modo, a cultura como sinônimo de identidade específica e irredutível entra no vocabulário da política e se torna uma linguagem de negociação entre movimentos sociais e Estado nacional (Ibid., p. 2).

Ora, se o conceito de cultura foi instrumentalizado politicamente a tal ponto de se tornar sinônimo de identidade, que potencial analítico essa categoria poderia ter no campo da Antropologia? Eis que a Antropologia do político se constitui como uma alternativa, melhor, como um instrumento teórico-metodológico que possibilita compreender "processos contemporâneos de reposição de 'alteridades' em termos de identidades e a produção de linguagens de negociação que produzam consenso em torno dos modos coletivamente aceitáveis de convivência entre as diferenças." (Ibid., p. 3).

O conceito de "mediação" entra em cena, pois na proposta da Antropologia do político os atores sociais tornam-se agentes na medida em que produzem e fazem a mediação de suas diferenças. Esses mediadores ou agenciadores entram no jogo político negociando estratégias e escolhas com o intuito de mobilizar lutas pelo poder de representação. Segundo Montero, Arruti e Pompa,

O que propomos como uma Antropologia do político tem, portanto, como foco o modo como os agentes mediadores ritualizam e negociam as categorias portadoras de identidades para a ação na esfera pública, propondo desta forma uma articulação entre cultura e política. Por meio do acompanhamento das trajetórias dos agentes a análise antropológica deve ser capaz de percorrer as mutações nos processos de significação e de legitimação que se realizam nas 
apropriações cada vez mais generalizantes de sentido ao longo desse arco que vai do ator, mais localizado ao agente político com maior capacidade de representar (Ibid., p. 32).

O intenso debate na Sociologia e na Antropologia sobre identidade decorre de um processo de mudanças que coloca em questão "quem classifica quem" e, portanto, a quem cabe decidir "quem é diferente de quem". Se conseguirmos investigar quem estabelece a diferença e para quem essa diferença é estabelecida, talvez percebamos que identidade não é uma categoria substantiva; ela é construída nas relações sociais.

Paula Montero nos mostra que a relação entre diferença e identidade é contemporânea e corrobora com a construção de categorias presentes nas mais variadas culturas para conhecer, classificar e pensar o outro (MONTERO, 1997, p. 50).

Apenas o ocidente construiu consistentemente ao longo da história de sua expansão julgamentos sobre o outro que visaram submete-lo e localizá-lo em posição de inferioridade (Ibid., p.50).

A autora define as noções "bárbaro", "pagão", "herege", "selvagem" como imagens construídas sobre diferentes culturas pelos europeus nos momentos de expansão: civilizações greco-romanas, descobrimentos ibéricos, formação dos grandes impérios coloniais, mundialização. Essas imagens traduzem os esquemas de pensamento ocidental mediante os quais na concepção do outro estão contidas as ideias de inferioridade e submissão (Ibid., pp.49-50). 
O ponto de mudança ocorre com os grandes modelos fundadores da disciplina antropológica: o Evolucionismo e o Funcionalismo. Ambas as correntes,

embora se propusessem a conhecer a diferença, criaram novas imagens sobre o outro, perpetuando, de certa maneira, aquelas do período anterior, ao projetar sobre a alteridade um novo etnocentrismo quando o homem primitivo é colocado no estágio inferior numa escala de raças ou quando sua cultura é essencializada em termos de etnias ou tradição. Isso perdura até as teorias antropológicas dos anos 50 (Ibid., pp. 55-56).

$\mathrm{Na}$ perspectiva dos estudos culturais, Kathryn Woodward argumenta que a identidade resulta de construções simbólicas e sociais. Essas construções marcam a identidade por um conjunto de diferenças que, dependendo do lugar e do momento, possuem graus variados de importância (WOODWARD, 2013, pp. 10-11).

A identidade é relacional e a diferença depende de uma marca simbólica estabelecida na relação entre identidades. Essa marca é o que confere sentido às práticas e relações sociais; quer dizer, "é por meio da diferenciação social que essas classificações da diferença são vividas nas relações sociais" (Ibid., pp.13-14).

Stuart Hall afirma que o tema da "identidade cultural" passou a ser muito discutido na teoria social devido ao fato de velhas identidades, que conferiam estabilidade ao mundo, entrarem em declínio após a consolidação da modernidade. Para ele, identidade cultural é definida pelos aspectos da identidade de cada um, resultado do "pertencimento" de cada indivíduo a culturas étnicas, raciais, linguísticas, religiosas e, acima de tudo, nacionais (HALL, 2005, pp. 7-8). 
$\mathrm{O}$ autor trabalha com a dicotomia identidade estável $\mathrm{x}$ identidade descentrada, identificando a existência de uma "crise de identidade" no indivíduo moderno devido a um processo de mudança.

Um tipo diferente de mudança estrutural está transformando as sociedades modernas no final do século XX. Isso está fragmentando as paisagens culturais de classe, gênero, sexualidade, etnia, raça e nacionalidade que, no passado, nos tinham fornecido sólidas localizações como indivíduos sociais. Estas transformações estão também mudando nossas identidades pessoais (Ibid., p.10).

Nesse sentido, Hall utiliza o conceito "pós-modernidade" para se referir à relação entre o sujeito e a identidade.

Esse processo produz o sujeito pós-moderno, conceptualizado como não tendo uma identidade fixa, essencial ou permanente. A identidade torna-se uma "celebração móvel”: formada e transformada continuamente em relação às formas pelas quais somos representados ou interpelados nos sistemas culturais que nos rodeiam. É definida historicamente e não biologicamente. O sujeito assume identidades diferentes em diferentes momentos, identidades que não são unificadas ao redor de um "eu" coerente (Ibid., pp. 12-13).

Hall contextualiza os processos de mudança social que problematizam a questão da identidade. Entretanto, o autor parece não distinguir os atores que jogam nesse quadro de mudanças. Se existiam velhas identidades, uma ancoragem estável e sólidas localizações, voltamos às questões iniciais e nos perguntamos: estável para quem?

A expressão "crise de identidade" não elucida com clareza as mudanças que configuram uma pós-modernidade de sujeitos descentrados. 
Longe de negar qualquer crise, parece-nos que somente apontar uma crise não é suficiente para uma compreensão da fragmentação de paisagens culturais muito menos do surgimento de sujeitos que assumem diferentes identidades em diferentes momentos.

Partindo da hipótese de que o nativo "descobriu" o sistema de classificação que estabeleceu qual identidade estava designada para cada um, aventamos que esse mesmo nativo passou a manipular as diferenças, tornando bastante complexa a noção de "pertencimento" (expressão que o próprio Hall utiliza entre aspas).

Em outras palavras, a afirmação e a negação de identidades escapa dos critérios tradicionais que cunharam uma "visão substantiva de cultura". Retomamos Montero (1997) para quem no lugar dessa visão substantiva ou essencialista entra em cena a noção relacional que promove o deslocamento da identidade do campo conceitual para o campo político (MONTERO, 1997, pp. 62-63).

Se queremos analisar, conforme a proposta do presente evento, a "complexidade na construção de uma suposta identidade brasileira" é importante adentrarmos nesse debate que traz à tona a crise do conceito de cultura no campo da Antropologia e a instrumentalização política que os agentes fazem na tentativa de ritualizar e negociar as categorias portadoras de identidades para a ação na esfera pública, fomentando uma articulação entre cultura e política.

Palavras Chave: Antropologia, Cultura, Política, Identidade

\section{Referências}

HALL, Stuart. A identidade cultural na pós-modernidade. Rio de Janeiro: DP\&A, 2005. 
KUPER, Adam. Cultura, a visão dos antropólogos. Bauru, Edusc, 2002.

MACAGNO, Lorenzo. “Uma antropologia do político?” In: Análise Social, 210, XLIX $\left(1^{\circ}\right)$, Universidade de Lisboa, 2014.

MONTERO, Paula, ARRUTI, José Maurício e POMPA, Cristina. "Para uma antropologia do político". In: A. G. Lavalle (org.). O horizonte da política: questões emergentes e agenda de pesquisa. São Paulo: Unesp, 2012.

MONTERO, Paula. "Globalização, identidade e diferença." In: Novos Estudos, n 49, 1997.

WOODWARD, Kathryn. "Identidade e diferença: uma introdução teórica e conceitual." In: Identidade e diferença: a perspectiva dos estudos culturais. Petrópolis: Vozes, 2013. 